\title{
CEREBRAL CIRCULATION AND METABOLISM IN SICKLE CELL AND OTHER CHRONIC ANEMIAS, WITH OBSERVATIONS ON THE EFFECTS OF OXYGEN INHALATION ${ }^{1}$
}

\author{
By ALBERT HEYMAN, JOHN L. PATTERSON, JR., AND T. WHATLEY DUKE \\ (From the Departments of Medicine and Physiology, Emory University School of Medicine, \\ and the Medical Service of Grady Memorial Hospital, Atlanta, Ga.)
}

(Submitted for publication March 13, 1952; accepted July 3, 1952)

Sickle cell anemia may be associated with a variety of serious cerebral manifestations, such as hemiplegia, aphasia, convulsions, stupor or coma $(1,2)$. These symptoms are usually attributed to thromboses of the cerebral vessels produced by sickled erythrocytes, vascular stasis and degenerative changes in the small and medium-size arteries of the central nervous system $(3,4)$. In chronic anemias from various causes, such mental manifestations as drowsiness, irritability, and fainting are often seen. Psychoses have been observed in pernicious anemia and in chronic posthemorrhagic anemia (5). A diminution in cerebral oxygen consumption in patients with pernicious anemia has been reported and may be the basis for the alterations in the mental status seen in these patients (6). It seemed worth-while for these reasons to study the cerebral circulation and metabolism in such patients, and this report presents the findings in 10 patients with sickle cell disease and eight patients with other types of chronic anemia. In order to obtain insight into the pathogenesis of the abnormalities observed, the effects of inhalation of $85-100 \%$ oxygen on cerebral functions were determined and the data thus obtained are also presented in this report.

\section{CASE MATERIAL AND METHODS}

The ages of the 10 patients with sickle cell anemia in this study varied from 13 to 34 years with an average of 24 years. All of the patients were Negroes; two were males and eight were females. Two of the patients (E. L., A. F.) had the onset of acute sickle cell crises several days prior to the cerebral studies. The remaining eight patients were in remission at the time of the studies. Evidence of sickle cell anemia had been present in all $10 \mathrm{pa}$ tients since childhood and included such symptoms as arthralgia, fever, abdominal pain, easy fatigability and,

\footnotetext{
1 This investigation was supported in part by a research grant from the U. S. Public Health Service, and in part by Contract N9onr92500, Office of Naval Research, Project Designation No. NR 112-607.
}

occasionally, dyspnea. All of them showed pallor of the mucous membranes, scars of old pretibial ulcers and dilatation of the retinal veins. Four patients had X-ray evidence of cardiac enlargement, but none had symptoms of congestive failure. Neurologic manifestations or evidence of mental retardation had not been observed.

Sherman's method for the determination of the percentage of sickled cells was employed (7). The number of abnormal cells in the internal jugular venous blood at the time of the cerebral studies ranged from $7 \%$ to $43 \%$, with a mean of $21 \%$. The number of true sickled cells was considerably less and averaged $3.6 \%$.

The group of eight patients with other types of chronic anemia comprised one patient (D. C.) with aplastic anemia, three with iron-deficiency anemia (R. C., E. T., O. J.), one with pernicious anemia (L. H.), and three with anemia caused by chronic blood loss from either hemorrhoids or menorrhagia (W. S., L. B., K. C.). The duration of anemia in these individuals ranged from six months to 11 years. They showed no manifestations of mental deterioration, neurologic involvement or congestive failure.

Ten patients convalescing from a variety of illnesses, such as gonorrheal arthritis, dermatitis and peptic ulcer, and from operations such as herniorrhaphy, were used as control subjects. These patients had only slight or no anemia and no evidence of intracranial or pulmonary complications.

The cerebral blood flow (CBF) was measured by the nitrous oxide method with minor modifications previously described $(8,9)$. The cerebral metabolic rate $\left(\mathrm{CMRO}_{2}\right)$ was calculated from the $\mathrm{CBF}$ and the cerebral arteriovenous oxygen difference. The cerebral vascular resistance (CVR) was calculated from the CBF and the mean arterial pressure measured directly from the femoral artery with a damped mercury manometer. Control observations of the cerebral circulation were performed with the patient breathing $21 \%$ oxygen, $15 \%$ nitrous oxide, and $64 \%$ nitrogen, following which the subject was given $100 \%$ oxygen by face mask for a period of 20 minutes. At the end of this time the gas was changed to $85 \%$ oxygen and $15 \%$ nitrous oxide, and a second blood flow determination carried out.

Samples of arterial and venous blood drawn just before and at the end of each blood flow procedure were pooled, and their $\mathrm{O}_{2}$ and $\mathrm{CO}_{2}$ content was measured by the combined procedure described by Peters and Van Slyke (10). The nitrous oxide content of blood sam- 
ples was determined by the manometric method of Orcutt and Waters (11). Modifications of these gasometric technics, suggested by Kety and Schmidt (8), were employed. Oxygen capacity of blood was obtained by equilibrating the sample with air in a small flask, analyzing for oxygen manometrically, and making the usual correction for dissolved oxygen. Hemoglobin concentration was calculated from the oxygen capacity. Arterial pH was measured with the glass electrode of a Cambridge Model $\mathrm{R} \mathrm{pH}$ meter and corrected to body temperature (12). Arterial $\mathrm{pCO}_{2}$ was calculated from the $\mathrm{pH}, \mathrm{CO}_{3}$ content and hematocrit by means of the nomogram of Singer and Hastings (13). Venous $\mathrm{pO}_{2}$ was calculated from the $\mathrm{pH}$ and the per cent oxyhemoglobin saturation, using the dissociation curves of Dill (14).

\section{RESULTS}

The mean cerebral blood flow in the patients with sickle cell anemia was found to be $72 \mathrm{cc} . / 100$ gm. brain/min., a value considerably higher $(\mathrm{p}<$ $.001)$ than the CBF of 49 cc. observed in the control patients (Table I, Figure 1). The patients with sickle cell anemia showed a wide range of $\mathrm{CBF}$ values from 50 to $91 \mathrm{cc}$. The eight patients with other types of chronic anemia had a mean CBF of 64 cc., a value significantly higher than the controls $(p<.02)$. There was some correlation between the hemoglobin level and the CBF in the sickle cell patients $(r=.66)$. The three patients (H. W., J. H., L. G.) with more than 10 gm. of hemoglobin per $100 \mathrm{cc}$. had a mean CBF value of $58 \mathrm{cc}$., while the seven patients with hemoglobin values of 5 to $7.7 \mathrm{gm}$. had a mean CBF of $78 \mathrm{cc}$.

Mean arterial pressure in both groups of anemic patients differed little from that found in the control subjects. The mean CVR of $1.3 \mathrm{~mm} . \mathrm{Hg} /$ cc. $/ 100 \mathrm{gm} . / \mathrm{min}$. in sickle cell anemia was significantly reduced below the control value. The mean CVR in the chronic anemias of other etiology was $1.5 \mathrm{~mm}$. $\mathrm{Hg}$, a value slightly higher than that found in the sickle cell patients.

The mean $\mathrm{CMRO}_{2}$ of the patients with sickle cell anemia was moderately reduced below that found in the control subjects and averaged 2.4 cc. $/ 100 \mathrm{gm}$. brain $/ \mathrm{min}$. $(.05>\mathrm{p}>.02)$. The two patients with the highest hemoglobin values (10.6 and $11 \mathrm{gm}$.) had normal values for cerebral oxygen consumption, while the patient (J. H.) with $10 \mathrm{gm}$. of hemoglobin had the low $\mathrm{CMRO}_{2}$ value of $2.1 \mathrm{cc}$. The mean arteriovenous oxygen difference in the sickle cell group was 3.5 vol. $\%$,

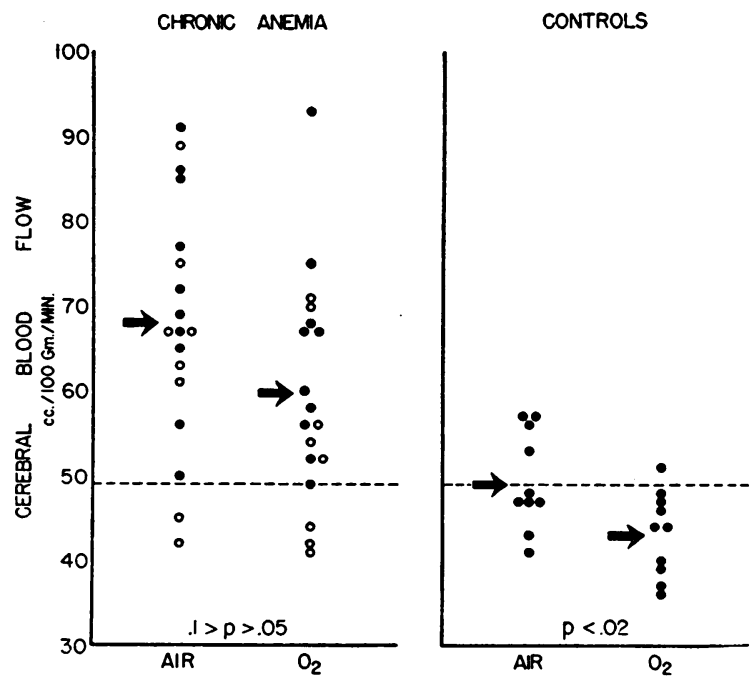

Fig. 1. Values for Cerebral Blood Flow in Individual Patients with Chronic Anemia and in Control Subjects Before and During Administration of 85-100\% OXYGEN

The solid dots in the anemia group represent patients with sickle cell anemia, and the open circles, patients with other types of anemia. The arrows indicate mean values in each group. The dotted line represents the average $\mathrm{CBF}$ in the control subjects breathing air.

in contrast to the control value of 5.9 vol. \%. A close correlation was observed between the arteriovenous oxygen difference and the hemoglobin values in the individual patients. The mean $\mathrm{CMRO}_{2}$ in the eight patients with other types of chronic anemia was $2.3 \mathrm{cc} . / 100 \mathrm{gm} . / \mathrm{min}$., a value comparable to that found in the sickle cell patients, but less than that of the controls $(.1>\mathrm{p}>.05)$. Two of the three patients in this group with normal values for cerebral oxygen consumption $(3 \mathrm{cc}$. or more) were young women (K. C., L. B.) with blood loss caused by menorrhagia. The third patient (E. T.) had anemia associated with nutritional deficiency. The mean value for jugular venous oxygen tension in the patients with sickle cell anemia was $28 \mathrm{~mm}$. $\mathrm{Hg}$, or $5 \mathrm{~mm}$. $\mathrm{Hg}$ less than that found in the control subjects. The mean arterial and venous $\mathrm{CO}_{2}$ tensions were both slightly lower in these patients than in the controls. The mean jugular venous $\mathrm{pO}_{2}$ in the patients with other types of chronic anemia was found to be $28 \mathrm{~mm}$. $\mathrm{Hg}$.

During inhalation of $85-100 \%$ oxygen all of the patients with anemia showed decreases in 


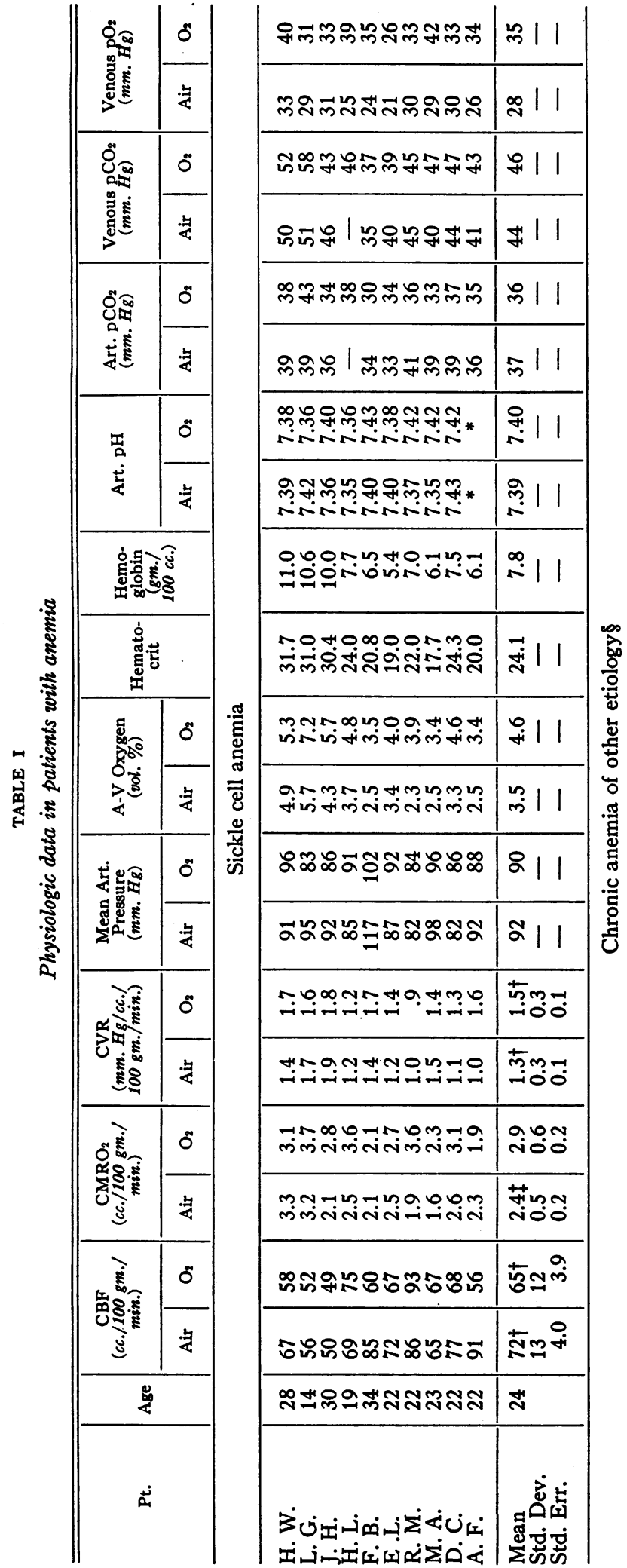

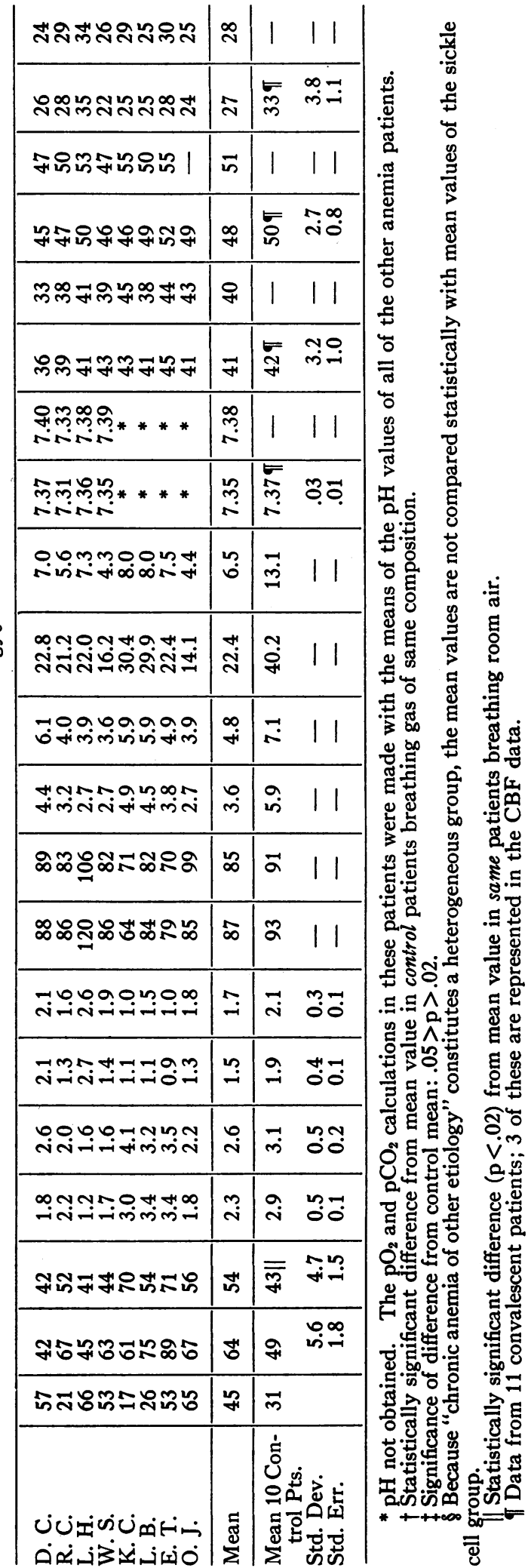


$\mathrm{CBF}$ and increases in CVR comparable to those found in the controls. Mean arterial pressure tended to diminish slightly in all groups. Despite the reduction in $\mathrm{CBF}$, the patients with sickle cell disease had a moderate increase in $\mathrm{CMRO}_{2}$ from a mean of 2.4 to $2.9 \mathrm{cc}$. with oxygen inhalation $(.1>\mathrm{p}>.05)$. This change was associated with an increase in arteriovenous oxygen difference from 3.5 to 4.6 vol. \%.

The eight patients with other types of chronic anemia also had a small mean increase in cerebral metabolism during oxygen administration. This change in $\mathrm{CMRO}_{2}$ from 2.3 to $2.6 \mathrm{cc}$. $/ 100 \mathrm{gm}$./ min. was statistically insignificant. The control subjects also had little change in $\mathrm{CMRO}_{2}$ with oxygen. The mean venous $\mathrm{pO}_{2}$ rose from 28 to $35 \mathrm{~mm} . \mathrm{Hg}$ in the patients with sickle cell anemia during oxygen inhalation, but did not change in the individuals with other types of anemia.

\section{DISCUSSION}

It is probable that the elevation of the cerebral blood flow observed in patients with chronic anemia resulted from a combination of factors. Since the arterial pressure in these patients differed only slightly from that in the controls, it is evident that vascular resistance was diminished. This could have been caused in part by the decrease in blood viscosity which resulted from the anemia (15), or by an increase in the caliber of the cerebral vessels.

Reduction in blood oxygen tension in the brain could have provided the stimulus for vasodilatation. The arterial oxygen tension has been found by Hickam (16) to be somewhat reduced in patients with severe anemia. It is evident that, unless a reduced arterial oxygen content is matched by an equivalent increase in blood flow, further abnormalities must follow : either the mean capillary and venous $\mathrm{O}_{2}$ tensions will undergo further decreases relative to the normal levels, or cerebral oxygen consumption will fall, or both. Actually, both conditions were found. It is not certain whether reduced capillary or venous $\mathrm{pO}_{2}$ per se represents a vasodilator stimulus, but it has been shown that a decrease in arterial oxygen saturation, produced by the inhalation of low-oxygen mixtures, results in cerebral vasodilatation (17). Changes in $\mathrm{pO}_{2}$ could not have been the only factor in producing the lowered vascular resistance in the patients with sickle cell anemia, since the cerebral blood flow failed to return to normal with the rise in venous $\mathrm{pO}_{2}$ to normal during oxygen inhalation.

The tendency for cerebral oxygen consumption to be reduced in the patients with chronic anemia, regardless of the etiology, raises the possibility that anemia itself can bring this about. The reduced venous $\mathrm{pO}_{2}$ found in the anemic patients is evidence that the cerebral tissue oxygen tension was also below normal. Although rapid reduction in arterial and jugular venous oxygen tension by the inhalation of $10 \%$ oxygen produces little or no change in cerebral metabolism (17), our observations suggest that prolonged reduction in tissue oxygen tension, produced by chronic anemia, may have an adverse effect on cerebral function. The increase in $\mathrm{CMRO}_{2}$ observed in several of the patients during oxygen inhalation lends some support to this view. The nerve cells of the brain in these patients were evidently capable of metabolizing at a higher level when presented with oxygen at a higher tension. Increase in $\mathrm{CMRO}_{2}$ during oxygen administration was not observed in the control subjects, or in our patients with cerebral vascular disease associated with hypertension and arteriosclerosis (18), or in patients with emphysema (19).

The extremely low $\mathrm{CMRO}_{2}$ values in some of the patients with sickle cell and other chronic anemias was rather surprising, in view of the normal mental state of the individuals. All of them were oriented, reasonably alert, and showed no neurologic or mental abnormalities. These observations are in contrast to those made in patients with pernicious anemia, in whom there appeared to be some correlation between abnormal mental status and cerebral oxygen consumption (6). It was believed, however, that in these patients the reduction in $\mathrm{CMRO}_{2}$ was not related so much to the degree of anemia as to the deficiency state causing pernicious anemia.

The fact that the $\mathrm{CBF}$ was high in two patients at the time of severe sickle cell crises is difficult to reconcile with the prevalent belief that vascular stasis occurs in a large proportion of cerebral vessels during this period and is the cause of neurologic manifestations. Although vascular thrombosis associated with circulatory stasis undoubtedly occurs in a number of these patients, it is also possible that many of the cerebral manifestations of sickle cell disease are caused by chronic hypoxia of the brain. 
It is apparent from the present studies, as well as those of Scheinberg (6), that the central nervous system suffers more profoundly in anemia than is generally appreciated.

\section{SUMMARY}

1. The cerebral blood flow (CBF), cerebral oxygen consumption $\left(\mathrm{CMRO}_{2}\right)$, and cerebral vascular resistance (CVR) were determined by the nitrous oxide technic, before and during the administration of $85-100 \%$ oxygen, in 10 patients with sickle cell anemia and eight patients with chronic anemia of other types.

2. The mean $\mathrm{CBF}$ in the patients with anemia as a group was significantly elevated, while the mean $\mathrm{CMRO}_{2}$ was moderately reduced below that of control subjects. There were only small differences between the mean values for cerebral blood flow and oxygen consumption in the two groups of anemic patients.

3. The administration of $85-100 \%$ oxygen in the patients with anemia was generally followed by a decrease in the CBF and an increase in CVR comparable to those found in the control subjects. The $\mathrm{CMRO}_{2}$ in many of the patients with anemia showed a rise during oxygen inhalation.

4. It is believed that the increase in cerebral blood flow in chronic anemia is caused by the combined effect of reduction in blood viscosity and vasodilatation from reduction in arterial, mean capillary and venous oxygen tensions. It is further suggested that the reduction in cerebral metabolism and possibly to some extent the mental symptoms observed in chronic anemia may be due to chronic tissue hypoxia. The increase in cerebral metabolism with oxygen inhalation in a number of the patients with anemia suggests that the use of oxygen may be a rational emergency therapeutic measure when mental symptoms are present.

\section{ACKNOWLEDGMENTS}

Dr. Charles M. Huguley, Jr., kindly performed the cell counts in the Sherman tests.

The technical assistance of the following is acknowledged with appreciation:

Mrs. Louise Thompson, and the Misses Voncile Williams, Mary Ruth Fordham, Mary Upshaw, and Elizabeth Kelley.

\section{REFERENCES}

1. Hughes, J. G., Diggs, L. W., and Gillespie, C. E., The involvement of the nervous system in sickle cell anemia. J. Pediat., 1940, 17, 166.
2. Arena, J M., Cerebral vascular lesions accompanying sickle-cell anemia. J. Pediat., 1939, 14, 745.

3. Bridgers, W. H., Cerebral vascular disease accompanying sickle cell anemia. Am. J. Path., 1939, $15,353$.

4. Thompson, R. K., Wagner, J. A., and MacLeod, C. M., Sickle cell disease. Report of a case with cerebral manifestations in the absence of anemia. Ann. Int. Med., 1948, 29, 921.

5. Romano, J., and Evans, J. W., Symptomatic psychosis in a case of secondary anemia. Arch. Neurol. \& Psychiat., 1938, 39, 1295.

6. Scheinberg, P., Cerebral blood flow and metabolism in pernicious anemia. Blood, 1951, 6, 213.

7. Sherman, I. J., The sickling phenomenon, with special reference to the differentiation of sickle cell anemia from the sickle cell trait. Bull. Johns Hopkins Hosp., 1940, 67, 309.

8. Kety, S. S., and Schmidt, C. F., The nitrous oxide method for the quantitative determination of cerebral blood flow in man: theory, procedure and normal values. J. Clin. Invest., 1948, 27, 476.

9. Patterson, J. L., Jr., Heyman, A., and Nichols, F. T., Jr., Cerebral blood flow and oxygen consumption in neurosyphilis. J. Clin. Invest., 1950, 29, 1327.

10. Peters, J. P., and Van Slyke, D. D., Quantitative Clinical Chemistry, Vol. II, Methods. Williams \& Wilkins, Baltimore, 1932.

11. Orcutt, F. S., and Waters, R. M., A method for the determination of cyclopropane, ethylene, and nitrous oxide in the blood with the Van Slyke-Neill manometric apparatus. J. Biol. Chem., 1937, 117, 509.

12. Rosenthal, T. B., Effect of temperature on $\mathrm{pH}$ of blood and plasma in vitro. J. Biol. Chem., 1948, 173, 25.

13. Singer, R. B., and Hastings, A. B., An improved clinical method for the estimation of disturbances of the acid-base balance of human blood. Medicine, 1948, 27, 223.

14. Handbook of Respiratory Data in Aviation. National Research Council, Washington, D. C., 1944.

15. Blumgart, H. L., and Altschule, M. D., Clinical significance of cardiac and respiratory adjustments in chronic anemia. Blood, 1948, 3, 329.

16. Ryan, J. M., and Hickam, J. B., The alveolar-arterial oxygen pressure gradient in anemia. J. Clin. Invest., 1952, 31, 188.

17. Kety, S. S., and Schmidt, C. F., The effects of altered arterial tensions of carbon dioxide and oxygen on cerebral blood flow and cerebral oxygen consumption of normal young men. J. Clin. Invest., 1948, 27, 484.

18. Heyman, A., Patterson, J. L., Jr., and Duke, T. W., The cerebral circulation and metabolism in cerebral vascular diseases. To be published.

19. Patterson, J. L., Jr., Heyman, A., and Duke, T. W., The cerebral circulation and metabolism in chronic pulmonary emphysema, with observations on the effects of inhalation of oxygen. Am. J. Med., 1952, $12,382$. 